\title{
Locating an insulinoma by surgical exploration
}

\author{
CAH Liyanage ${ }^{1}, K_{\text {Rajaratnam }}^{2}$ and RS Zanoon ${ }^{3}$
}

\begin{abstract}
The case of a 79-year old man who was suspected to have an insulinoma is presented. Although clinically and biochemically an insulinoma was the most probable diagnosis there was no supportive radiological evidence. Open surgery and exploration revealed a lesion which was confirmed to be an insulinoma. The patient's hypoglycaemia improved immediately following surgery. In the Sri Lankan setting where sophisticated imaging procedures are not freely available, open exploration of the pancreas is a good alternative to locate a suspected insulinoma.
\end{abstract}

\section{Introduction}

Insulinoma, the commonest neuroendocrine tumour that occurs in the pancreas, has a $10-15 \%$ preponderance of being malignant [1]. The mean age of presentation is about 45 years [1]. The usual clinical presentation is intractable hypoglycaemia or complications of hypoglycaemia. The insulin : glucose ratio is also elevated. The presence of hypoglycaemia with an inappropriate increase in the insulin levels is the key to diagnosis. After biochemical diagnosis, the lesion needs to be localised. The ultrasound scan (USS) and computerised tomography (CT) are the two common investigations performed, though they detect only $50 \%$ of the lesions. Magnetic resonance imaging (MRI) has a slightly better yield compared to CT and the USS. However, at the hands of an experienced surgeon there is an $80 \%$ chance of correctly localising the lesion at open exploration of the pancreas [1].

In specialised centres transhepatic portal venous sampling is used to locate the insulinoma. The 75-80\% of insulinomas are solitary benign lesions, $10 \%$ occur as multiple adenomas in multiple endocrine neoplasia 1 (MEN1) [2] and 10\% are malignant. These metastasise to the liver and are slow growing. Most benign lesions are $0.5-2 \mathrm{~cm}$ in size whereas malignant lesions are about $6 \mathrm{~cm}$ in size. Once the lesion is located it is enucleated. Where the tumour is not found and facilities are available, intraoperative ultrasonography can be done to locate the lesion [3]. Still if the lesion is not found and if the glycaemic control is satisfactory, surgery would be abandoned and transhepatic portal venous sampling attempted later $[4,5]$. If there is uncontrollable hypoglycaemia, distal resection of the pancreas is advocated [6]. The non-surgical management of this condition includes feeding small frequent meals, administering diazoxide
[7], which reduces insulin secretion in $60 \%$ of patients, and treatment with octreotide. Usually there is immediate restoration of the glycaemic control after surgery. There could be immediate post-operative hypoglycaemia as a result of the release of insulin due to handling of the pancreas [8].

\section{Case report}

A 79-year old man was transferred to a neurology unit at the National Hospital of Sri Lanka, following an altered level of consciousness after cataract surgery. A CT brain revealed multiple infarcts. The patient was found to be having hypoglycaemic attacks with capillary glucose levels going down to $1.1-1.6 \mathrm{mmol} / \mathrm{L}$. His serum insulin level was $24.5 \mu \mathrm{U} / \mathrm{mL}$ ( $>20 \mu \mathrm{U} / \mathrm{mL}$ diagnostic). Insulin: glucose ratio was $0.8(<0.3)$. The growth hormone level was $0.8 \mathrm{mU} / \mathrm{mL}$ and cortisol $871 \mathrm{mmol} / \mathrm{L}$. His IV and oral contrast CT abdomen showed multiple hypoechoic areas in the liver. The USS abdomen was normal and MRI scan was not available. Colonoscopy was normal up to the ascending colon and flexible gastroduodenoscopy revealed small polyps in the stomach, which showed a normal gastric mucosal pattern. USS guided and CT guided biopsy of the liver lesions also revealed normal liver architecture.

Because of the severe hypoglycaemia he was started on a continuous $10 \%$ glucose infusion and the capillary glucose was monitored regularly. The patient underwent laparoscopic examination and laparoscopy guided liver biopsy. Pancreatic lesions could not be visualised and the biopsy showed normal liver cells. Subsequently, the patient underwent exploratory laparotomy for locating the insulinoma. At surgery a $1 \mathrm{~cm}$ x $1 \mathrm{~cm}$ firm, vascular, blood red encapsulated lesion was found at the superior pole of the pancreas. The lesion with the capsule was easily shelled out. A liver biopsy was also done from a suspicious area. On the first post-operative day the patient was not hypoglycaemic. His dextrose infusions were tailed off. On the fifth day blood glucose rose to levels that warranted introduction of an oral hypoglycaemic agent.

\section{Discussion}

In this patient the biochemical diagnosis was made early. However, the location of the insulinoma $[9,10]$ with the available resources was difficult. The liver lesions

\footnotetext{
${ }^{1}$ Registrar in Surgery, ${ }^{2}$ Senior Registrar in Surgery, ${ }^{3}$ Surgeon, National Hospital of Sri Lanka. Correspondence: CAHL, Tel: +94 10777749459 , e-mail: <chandikaliyanage@hotmail.com > (Competing interests: none declared). Received 3 February 2004 and accepted 15 February 2004.
} 
were repeatedly biopsied and found to be normal. Hence, the possibility of a malignant insulin secreting tumour was ruled out. An open exploration was done and the lesion we removed was confirmed to be an insulinoma without any features of malignancy. In the Sri Lankan context, with limited facilities, open exploration of the pancreas for location of an insulinoma appears to be a useful procedure in the management of this condition.

\section{References}

1. Rattner DW. Insulinomas and other tumours. In: Morris PJ, Malt RA, eds. Oxford Text Book of Surgery. v.1. New York: Oxford University Press, 1994; 1317-20.

2. Cougard P, Goudet P, Peix JL, Henry JF, Sarfati E, et al. Insulinomas in multiple endocrine neoplasia type 1. Report of a series of 44 cases by the multiple endocrine neoplasia study group. Annales De Chirurgie 2000; 125: 118-23.

3. Lo CY, Lo CM, Fan ST. Role of laparoscopic ultrasonography in intraoperative localization of pancreatic insulinoma. Surgical Endoscopy 2000; 14: 1131-5.

4. Dunn E, Stein S. Percutaneous transhepatic pancreatic vein catheterization in localization of insulinoma. Archives of Surgery 1981; 116: 232-3.
5. Stefanini P, Carboni M, Patrassi N, De Bernardinis G, Negro $\mathrm{P}$, et al. The value of arteriography in the diagnosis and treatment of insulinomas. American Journal of Surgery 1976; 131: 352-6.

6. Hirshberg B, Libutti SK, Alexander HR, Bartlett DL, Cochran C, et al. Blind distal pancreatectomy for occult insulinoma, an inadvisable procedure. Journal of the American College of Surgeons 2002; 194: 761-4.

7. Mateu MV, Gonzalez Pardo FO, Cristino A, Lasdica S, Fainstein D. Treatment of insulinoma with diazoxide. Medicina (Buenos Aires) 2003; 63: 51-3. [In spanish]

8. Amikura K, Nakamura R, Arai K, Kobari M, Matsuno S. Role of intraoperative insulin monitoring in surgical management of insulinoma. Journal of Laparoendoscopic and Advanced Surgical Techniques 2001; 11: 193-9.

9. Marubayashi S, Tanaka T, Shimizu Y, Matugu Y, Fukuma $\mathrm{K}$, et al. Tumor localization studies and surgical treatment in patients with insulinoma. Hiroshima Journal of Medical Sciences 1998; 47: 69-72.

10. Azimuddin K, Chamberlain RS. Tumor localization studies and surgical treatment in patients with insulinoma. Surgical Clinics of North America 2001; 10: 511-25.

\section{Passive smoking and coronary heart disease}

High overall exposure to passive smoking seems to be associated with a greater excess risk of CHD than partner smoking and is widespread in non-smokers, suggesting that the effects of passive smoking may have been underestimated in earlier studies. Our results add to the weight of evidence suggesting that exposure to passive smoking is a public health hazard and should be minimised.

PH Whincup, JA Gilg, JR Emberson, MJ Jarvis, C Feyerabend, et al. Passive smoking and risk of coronary heart disease and stroke: prospective study with cotinine measurement. British Medical Journal 2004;329:200-4.

\section{Resisting cookbook medicine}

The HRT fiasco eloquently illustrates the potential shortcomings of doctrinaire clinical directives and highlights the progressive role of thoughtful dissent in the evolution of medical thought. Perhaps it is time to reevaluate the tendency to regard authoritative documents as dogma and time to foster a healthy tension between autonomy and professional standards.

SJ Genuis, SK Genuis. Resisting cookbook medicine. British Medical Journal 2004;329:179 